\title{
Breath of life: the evolution of oxygen therapy
}

\author{
C Grainge MRCP
}

J R Soc Med 2004;97:489-493

Between 1771 and 1772 the Swedish pharmacist Karl Scheele did a series of experiments with mercuric oxide and potassium nitrate. On heating the two he obtained a gas that caused candles to burn more brightly. He did not, however, rush to publication. By the time the observation was published, in 1777, Scheele had been overtaken by the English theologian-chemist Joseph Priestley. Working independently in 1774, Priestley had heated mercuric oxide and obtained what he described as 'dephlogisticated air' - an experiment reported in 1775. The gas discovered by Scheele and Priestley was oxygen - the agent ubiquitous in modern medicine.

\section{PHLOGISTON THEORY}

Priestley's nomenclature was derived from the 'phlogiston' theory - the chemical wisdom of the time. This theory stated that fires released their phlogiston or combustible components into the atmosphere. By gently heating a burnt substance such as mercuric oxide, Priestley believed he was removing phlogiston from the atmosphere into the mercury, so purifying the air. Hence the term dephlogisticated air, which he describes inhaling in his Experiments and Observations on Different Kinds of Air: ${ }^{1}$

'The feeling of it to my lungs was not sensibly different from that of common air; but I fancied that my breast felt peculiarly light and easy for some time afterwards. Who can tell but that, in time, this pure air may become a fashionable article in luxury. Hitherto only two mice and myself have had the privilege of breathing it.'

The dephlogisticated air was oxygen released from the previously burnt mercury. With the advent of 'oxygen bars' on high streets in New York and Berlin where individuals pay around $\$ 10$ for 5 minutes of oxygen therapy, Priestley seems remarkably prescient in his suggestion that oxygen might become a fashionable luxury article. Priestley also conjectured on possible medical applications and restrictions for dephlogisticated air:

'From the greater strength and vivacity of the flame of a candle, in this pure air, it may be conjectured, that it

Derriford Hospital, Derriford Road, Plymouth PL6 8DH, UK

E-mail: chrsgrain@doctors.org.uk might be peculiarly salutary to the lungs in certain morbid cases, when the common air would not be sufficient to carry off the putrid effluvium fast enough. But, perhaps, we may also infer from these experiments, that though pure dephlogisticated air might be very useful as a medicine, it might not be so proper for us in the usual healthy state of the body; for, as a candle burns out much faster in dephlogisticated than in common air, so we might, as may be said, live out too fast, and the animal powers be too soon exhausted in this pure kind of air. A moralist, at least, may say, that the air which nature has provided for us is as good as we deserve.'

Correction of the phlogiston theory awaited the work of Antoine Lavoisier, who named the gas oxygène, meaning acid former, in 1778. The transfer from laboratory bench to formulary came quickly, with the first therapeutic use of the newly named gas only eight years after Priestley's publication. In 1783 the French physician Caillens treated a young woman with phthisis (tuberculosis) who 'very much benefited' from daily inhalations of oxygen.

\section{THE LUNAR SOCIETY AND THE PNEUMATIC INSTITUTION}

Joseph Priestley was a member of the Lunar Society of Birmingham, an exclusive group whose aim was to encourage transfer of new scientific knowledge to industry. Its members met every month on the night of the full moon-allegedly so as to allow members to walk home safely by moonlight, through the normally dark and unpoliced streets of the city. Membership included Josiah Wedgwood, Erasmus Darwin (grandfather of Charles) and the physicist James Watt. Probably it was at a meeting of the 'Lunarticks' that Watt learned from Priestley about the new dephlogisticated air; this may have been the reason why Watt joined Thomas Beddoes when he founded the Pneumatic Institution in Bristol in 1799. ${ }^{2}$ Another recruit was the engineer Humphrey Davy, inventor of the miner's safety lamp.

The Pneumatic Institution was based at the 'upper end of Dowry-Square, Hotwells, corner house' and administered oxygen free of charge to 'out-patients . . . in consumption, asthma, palsy, dropsy, obstinate venereal complaints, scrophula or King's Evil and other diseases, which ordinary means have failed to remove'. 
Watt, Davy and their colleagues at the Pneumatic Institution made no claim for cure; they informed patients that their aim was the investigation of the efficacy of oxygen in treatment of disease. In the short inhalations the concentration of oxygen was usually higher but sometimes lower than that in normal air. Typical therapy was 'a pint of oxygen air in a bagful of common air, that is to say, diluted 20 to 40 times its bulk of common air and gradually increase the dose as the symptoms direct: observing always to dilute with at least 20 times the quantity of common air'. This mixture would have provided approximately $23-28 \%$ oxygen. Higher concentrations were considered however: 'if pure oxygen air is inhaled, it will be found on emission from the lungs, to be still highly dephlogisticated; but when diluted it has more time to act, and more of it is probably absorbed'.

Many of the techniques developed by the Pneumatic Institution are still used today, including corrugated noncrushable breathing tubes, mouthpieces and the method for mass production of gases devised by Watt. The Institution was converted into a normal hospital to cope with the outbreak of typhus in Bristol in the autumn of 1800. This brought to a halt the rational and scientific investigation of oxygen therapy until the work of Haldane and others nearly a century later.

\section{THE DARK AGES OF OXYGEN THERAPY}

During the 1800s, after the closure of the Pneumatic Institution, oxygen administered in short spells was widely touted as a panacea. The Lancet and the British Medical Journal published many papers in the mid 1800 s by a Dr S B Birch, extolling the virtues of oxygen. These culminated in his 1869 Lancet publication advocating the use of oxygenated bread and water. ${ }^{3}$ History repeats itself: 'oxygenated water' is now available in many shops, and the marketing slogans are very similar to the claims made for oxygen over a century ago:

'Most people report that Oxygen Water gives them extra energy and makes them more alert . . . the effects of inadequate oxygen in the blood are well known. Drinking oxygenated water gives you another path for bringing oxygen into your blood'. 4

Even when Dr Birch and his contemporaries advocated inhalation of gaseous oxygen, the recommended doses were small, typical therapy being 'four gallons morning and evening', usually delivered by wafting oxygen from a bucket towards the face of the patient.

Throughout the 19th century little true oxygen therapy was available to the public, but there were many advertisements for 'compound oxygen'. Advertised as a cure-all, this seldom contained any molecular oxygen at all. Most often it was dilute nitrous oxide, combined with ferric carbonate or potassium chlorate to give it colour and convince patients they were obtaining benefit - in much the same way as oxygen provided in modern oxygen bars is bubbled through coloured water. The manufacturers stated in one pamphlet:

'In the Compound Oxygen the proportion of the elements is so altered that the oxygen is greatly in excess. And in the manufacture of it, the oxygen is magnetized; which gives to it the quality known by scientists as "Ozone".'

The pamphlet was published in Philadelphia, where the authors GR Starkey MD, and GE Paten BMD offered compound oxygen for both home treatment and in their opulent 'oxygen parlour'. ${ }^{5}$ No charge was made for 'advice or consultation':

'The HOME TREATMENT is sent by Express, at the cost of the person ordering it, on the receipt of the price, which is $\$ 15.00$. It contains two months' supply of "Compound Oxygen", with inhaling apparatus, and full and explicit directions for use.'

Today the equivalent cost would be about $\$ 275$, or $£ 160$, to inhale a dilute preparation of nitrous oxide. More expensive was treatment in the parlour: 'The fee for this Treatment is $\$ 30.00$ per month, payable in advance. This calls for thirty treatments'.

Not surprisingly this trade in useless therapy had its critics - for example, Samuel S Wallian MD, who wrote in 1886 that

'Most of these advertisers name their "secret" preparation "compound oxygen". As to their nature, all are about alike; and it ought to be unnecessary to repeat to intelligent physicians that none of them contain any free oxygen ... . that these solutions are useful is quintessence of bosh. The exercise of a grain of chemical common sense will render all this pretensious nonsense.' ${ }^{6}$

\section{CONTINUOUS ADMINISTRATION OF OXYGEN}

Four years after Wallian expressed his disgust at the purveyors of compound oxygen, Dr Albert Blodgett reported in the Boston Medical and Surgical Journal a new variant of oxygen therapy, in a woman of 46 with pneumonia: ${ }^{7}$ 
'When I directed the continuous administration of the gas, I did so under the positive conviction that the patient was irrevocably doomed, and the best result that I looked for, was simply relief to the sensation of suffocation, and not any curative action ... At this time I had only employed the gas in the manner ordinarily directed, that is, two or three gallons at a time, several times daily. I now directed its use without cessation, and to my great surprise, the patient not only obtained the relief desired, but was enabled to carry on the function of respiration. The amount of gas employed was not far from two hundred gallons in twenty four hours.'

This is the first record of the continuous administration of oxygen gas, in this instance at about $6 \mathrm{~L} / \mathrm{min}$. In modern terms this was a paltry dose. Nevertheless Blodgett was at pains to point out that he attempted this treatment in desperation; moreover,

'The dealer who supplied the gas was astonished at the amount required, and, thinking to do me a service, sent me a cautionary message, implying that no human being could possibly stand so great an amount of oxygen, on account of the dangerous degree of stimulation to the system and the increased combustion of tissue.'

This warning brings to mind the comments of Priestley that in breathing oxygen we might 'live out too fast, and the animal powers be too soon exhausted'; little progress in the understanding of respiratory physiology had been made in the intervening one hundred years.

This first description of a step change in the clinical delivery of oxygen was published in competition with many papers from less perceptive individuals advocating methods for administering the gas that have not stood the test of time. Contemporary publications advocated oxygen administration via the stomach for resuscitation, via the urethra for inflammatory conditions and by enema for the treatment of gallstones (a proposal published in the Journal of the American Medical Association by JH Kellogg MD). ${ }^{8}$

\section{THE ORIGIN OF MODERN OXYGEN THERAPY}

In the 25 years after Blodgett's paper, progress in oxygen therapy accelerated sharply, partly through advances in basic science and medicine and partly because of the horrors of gas poisoning in the trenches of the First World War. In the early years of the 20th century, two physiologists, Adolph Fick (German) and Paul Bert (French) greatly advanced the understanding of basic oxygen physiology by describing oxygen tension in terms of units of partial pressure. They used those units to describe the difference in oxygenation between arterial and venous blood, relating this difference to tissue oxygen consumption and cardiac output; they also described central nervous system toxicity at high oxygen tensions.

The individual who built on their work and brought oxygen therapy to a rational and scientific basis was John Scott Haldane (1860-1936), who graduated in medicine from Edinburgh University in 1884 and held his first professional position at Queen's College, Dundee, then part of St Andrew's University.

Haldane published 'The therapeutic administration of oxygen' in early 1917 while reader in physiology at Oxford University. ${ }^{9}$ This paper represents the origin of rational oxygen use, containing little that has been fundamentally superseded today. Haldane describes in detail the regulation of respiratory drive by carbon dioxide and its effects on blood hydrogen ion concentration. He explains the concept of anoxaemia, which he classifies under three types - lack of oxygen, lack of haemoglobin, or lack of circulation. ${ }^{10} \mathrm{He}$ also includes notes on the tissue rather than blood anoxia that is found in carbon monoxide poisoning. The newly discovered central nervous system and pulmonary toxicity of oxygen are noted. Haldane identifies the fundamental requirement - beyond the technology of the day - to know what percentage is being breathed. Perhaps the most forward-looking concept in this work is that of ventilationperfusion matching. Haldane describes the situation of pneumonia

'when a portion of the lungs, including even the greater portion of both lungs, is entirely blocked by consolidation, there is commonly no cyanosis. This indicates that there is very little blood passing through the consolidated parts. What passes through the healthy portion is sufficient for respiratory requirements during rest . . . When cyanosis due to a lung affection exists, in spite of the fact that air is entering the whole or great part of the lungs freely, we seem driven to the conclusion that the entry of oxygen in the blood through the alveolar walls is impeded by exudation and increase in the thickness of the alveolar walls.'

He goes on to show how the carbon dioxide concentrations do not rise in the latter situation because carbon dioxide is more soluble than oxygen. His solution for 'hindered passage of oxygen through alveolar walls' is 'raising the percentage of oxygen in the alveolar air and so increasing the diffusion pressure.'

Haldane also noted that

'It may be argued that such measures as the administration of oxygen are at best only palliative and are no real use, since they do not remove the cause of 
the pathological condition. As a physiologist, I cannot for a moment agree with this reasoning. The living body is no machine, but an organism constantly tending to maintain or revert to the normal, and the respite afforded by such measures as the temporary administration of oxygen is not wasted, but utilized for recuperation.'

A reader today might find the terminology dated and the concepts simplistic. In the light of modern knowledge it is easy to underestimate the intellectual leap made by Haldane; a huge gulf had opened between him and his contemporaries. For example, at the time when Haldane was writing in terms of ventilation-perfusion mismatching, others were recommending treatment with subcutaneous oxygen gas. ${ }^{11}$ His genius was recognized by the Royal Society with the award of the Queen's Medal in 1916 and the Copley Medal in 1934.

\section{OXYGEN IN THE FIRST WORLD WAR}

Haldane's expertise came to the fore with the outbreak of World War One when poison gas was deployed on the battlefield. The matter may have been brought particularly to his attention by his son, who had enlisted in the Black Watch at the outbreak of war and had served at the front.

Oxygen was primarily used in treatment of poisoning by phosgene (a gas first synthesized by Humphrey Davy). Phosgene could be used alone, forming a white cloud smelling of freshly mown hay, and being heavier than air would roll down hills into trenches. It was also used in combination with chlorine as 'white star'. Phosgene acts partly by forming hydrochloric acid when combining with water in the lungs, causing alveolar damage. At low doses it results in mild cough and exercise dyspnoea; at high doses it causes pulmonary oedema 6-10 hours after exposure, leading to an acute respiratory distress syndrome. Between 1916 and 1917 there were over 17000 casualties from gas poisoning. Phosgene is still employed in the manufacture of plastics and dyes, and could be used as a terror weapon.

The use of oxygen on the battlefields of the First World War was documented at the time and a report was published in the British Medical Journal at the end of hostilities. ${ }^{12}$ This early report contains much that is taken for granted today. It highlights obstacles to the supply and administration of oxygen that remain troublesome even now.

Treatment of soldiers and munitions workers who had been gassed was attempted in both the acute and the chronic phases of poisoning. Acute poisoning, after initial triage, was managed with portable equipment as near to the site of injury as possible. This 'Haldane equipment' reservoir bag attached to the regulator (rather than on the mask as today), and a tight-fitting mask with non-return valves.

One difficulty with such oxygen therapy was that 'the oxygen was expended on the surrounding air and not the patient'. The 'necessity for continuity of administration as long as symptoms of anoxaemia persist' was identified, and junior medical officers were berated for their 'alarm at the apparatus' and for 'giving oxygen for five minutes only in each hour. Such a proceeding was useless'. Another complication in acute phosgene poisoning was that the profuse lung oedema filled the tightly fitting masks; consequently the Haldane face mask was abandoned in favour of nasal prongs (developed in the field by Captain Adrian Stokes RAMC). It was also noted that oxygen was useful in acute treatment of 'lung oedema of trench nephritis, acute purulent bronchitis, and severe haemorrhage.' The cause of trench nephritis, which had a case fatality rate exceeding $10 \%$, may have been hantavirus infection. ${ }^{13}$

Nocturnal dyspnoea and poor exercise tolerance remained troublesome in many gassed soldiers long after exposure and a large static treatment facility was established in Cambridge:

' . . . a glass room about 1,000 feet capacity formed a living ward and contained three beds. The ward was gas tight and fitted with air locks. The composition of the atmosphere was kept at 40-50 per cent of oxygen. The $\mathrm{CO}_{2}$ and aqueous vapours were removed by passing the air from the ward through an external circuit containing scrubbers of soda-lime and calcium chloride and potassium permanganate'.

The report describes how investigation into oxygen use was single blinded. In some cases 'the patient believe[d] that he was getting the treatment, while in reality he was not doing so ... . he complained that the treatment did him no good ... the oxygen treatment really began and he at once improved'.

By the end of the First World War, a core knowledge had been developed regarding rational use of oxygen. The treatment was known from single-blinded experiments to improve survival in acute gas poisoning and to lessen morbidity in the chronic phase. Techniques were available for administering oxygen from a pressurized cylinder, with a reservoir bag to increase inspired oxygen concentration and via nasal prongs for those patients who could not tolerate a mask. Firm evidence for the utility of oxygen in trauma care was acquired, and intermittent treatment was seen to be useless. Where less mobile equipment was applicable, the principles and practice of oxygen rebreathing equipment had been tested in a large trial. Virtually none of 
these techniques has changed to the present day, though rebreathing technology is generally limited to diving recompression chambers and specialist anaesthetic circuits. Strangely, the report makes no mention of the difficulties of transporting oxygen cylinders around the battlefield.

\section{FURTHER DEVELOPMENT OF OXYGEN THERAPY}

With further publications by Haldane, including his book Respiration in $1922,{ }^{14}$ the pace of understanding accelerated. The effect of therapeutic oxygen on survival was described in 1928. The benefit of oxygen therapy had been identified, but there was still reluctance on the part of the medical profession to administer oxygen continuously despite the battlefield experience regarding which Haldane was quoted as saying that 'intermittent oxygen therapy is like bringing a drowning man to the surface of the water-occasionally'. This comment was echoed by Christie, writing in 1938 about the benefits of continuous oxygen administration:

' . . . to give oxygen once every two hours to a patient with broncho-pneumonia may be equivalent to placing him on top of Mount Everest and bringing him back to sea level every two hours for a breather'.

Only in 1962 was it was demonstrated that, with intermittent oxygen therapy, treatment is followed by arterial hypoxaemia worse than that before treatment. ${ }^{15}$ The results of the first study of truly long-term oxygen therapy, given for up to 41 months to chronic bronchitics living in Denver, Colorado, were published in $1968 .{ }^{16}$ Yet in 1972 over $10 \%$ of physicians involved in intensive therapy still prescribed intermittent oxygen. ${ }^{17}$

Nowadays, supplemental oxygen is a vital part of prehospital and hospital trauma care, the practice of anaesthesia, the management of most forms of respiratory distress and the treatment of many other acute and chronic medical conditions. It is used so frequently that it is often taken for granted; yet one must not forget that above atmospheric concentrations it should be considered a drug and prescribed accordingly. The ability of modern physicians to prescribe such treatment owes much to the pioneering work of Priestley, Lavoisier, Davy, Watt, Fick, Haldane and many young medical officers working on the battlefields of France.

Acknowledgment I thank Dr Mary Heber and Dr Peter Mahoney for their interest and helpful suggestions.

\section{REFERENCES}

1 Priestley J. Experiments and Observations on Different Kinds of Air. Birmingham: Thomas Pearson, 1775

2 Beddoes T. The Pneumatic Institution for gas therapy. Bristol Gazette and Public Advertiser, 21 March 1799

3 Birch JS. Some remarks on the exhibition of oxygen as a therapeutic, in connexion with a new, agreeable, and easy form of administration by the stomach. Lancet. 1869;i:492

4 Nice Toys Inc. [www.nicetoys.com/hiosilverwaterfigs.html] accessed 18.8.04

5 Starkey GR. Compound Oxygen-its Mode of Action and Results. Philadelphia: Starkey \& Palen, 1881

6 Wallian SS. Further report: on oxygen as a therapeutic agent. Med Record. 1885;31:483-8

7 Blodgett AN. The continuous inhalation of oxygen in cases of pneumonia otherwise fatal, and in other diseases. Boston Med Surg J 1890; $123: 481-4$

8 Kellogg JH. Oxygen enemata as a remedy in certain diseases of the liver and intestinal tract. JAMA 1888;11:258-62

9 Haldane JS. The therapeutic administration of oxygen. BMJ 1917; i: $181-3$

10 Haldane JS. A lecture on the symptoms, causes and prevention of anoxaemia (insufficient supply of oxygen to the tissues) and the value of oxygen in its treatment. BMJ 1919;ii:65

11 Howitt HO. The subcutaneous injection of oxygen gas. Can Med Assoc J 1914;4:983-5

12 Report of Societies. Oxygen therapy. BMJ 1920;i:150-2

13 Cameron JS. The history of viral haemorrhagic fever with renal disease (hantavirus) Nephrol Dial Transplant 2001;16:1289-90

14 Haldane JS. Respiration. London: Oxford University Press, 1922

15 Massaro DJ, Katz S, Luchsinger PC. Effects of various modes of oxygen administration on the arterial gas values in patients with respiratory acidosis. BMJ 1962;ii:627-30

16 Petty TL, Finigan MM. Clinical evaluation of prolonged ambulatory oxygen therapy in chronic airway obstruction. Am J Med 1968;45:242-6

17 Leigh JM. Early treatment with oxygen. Anaesthesia 1974;29:194-208 